Mr Ljubiša Brkić, potpukovnik, dipl. inž. VP 3001 Beograd

\section{OCENA POGODNOSTI ODRŽAVANJA VOZILA SPECIJALNE NAMENE}

UDC: $623.437 .4-7$

Rezime:

Na osnovu podataka dobijenih iz eksploatacije, za motor konkretnog vozila specijalne namene izvršena je ocena funkcije pogodnosti održavanja, kao konstrukcijske karakteristike, metodom raspodele vremena trajanja postupaka održavanja kao kumulativne funkcije verovatnoće. Na osnovu dobijene ocene izvršena je analiza srednjeg vremena trajanja korektivnih održavanja, kao i ispunjavanje takticko-tehničkih zahteva.

Ključne reči: pogodnost održavanja, postupci održavanja, sistem održavanja, vreme trajanja održavanja.

\title{
EVALUATION OF MAINTAINABILITY OF SPECIAL PURPOSE VEHICLES
}

\section{Summary:}

In this work, based on data which are taken from real service for the engine of $a$ particular vehicle, evaluation of the maintainability was carried out using the distribution method of long - lasing time of the procedure of maintenance like the cumulative function of probability. Based on the obtained evaluation the analysis of the Mean Time To Repair (MTTR) was carried out as well as the meeting the Tactical-technical requirements.

Key words: maintainability, procedure of maintenance, maintenance system, long - lasting time od maintenance.

\section{Uvod}

Pogodnost održavanja vozila jedna je od važnijih konstrukcijskih karakteristika koja se može opisati vremenima trajanja postupaka održavanja. Pogodnost održavanja predstavlja verovatnoću da će se potrebni postupci održavanja obaviti do određenog vremena pod određenim uslovima [1].

$\mathrm{Na}$ osnovu podataka dobijenih iz eksploatacije, za motor konkretnog vozila specijalne namene izvršena je ocena funkcije pogodnosti održavanja kao konstrukcijske karakteristike metodom raspodele vremena trajanja postupaka održavanja kao kumulativne funkcije verovatnoće. Raspodelom vremena trajanja postupka održavanja može se opisati pogodnost održavanja kao konstrukcijska karakteristika vozila.

\section{Teorijska razmatranja}

Pogodnost održavanja je multidisciplinarna karakteristika koja je usko pove- 
zana sa pouzdanošću vozila, njegovom bezbednošću, obučenošću ljudskog faktora u korišćenju i održavanju i logističkom podrškom.

Zadatak pogodnosti održavanja jeste da obezbedi maksimalnu gotovost i raspoloživost vozila uz minimalne troškove održavanja i minimalne zastoje, odnosno minimalno vreme održavanja uz minimalnu logističku podršku.

Funkcija pogodnosti održavanja izražava se preko vremena trajanja postupaka održavanja $\left(t_{o}\right)$ i može se izraziti u obliku [1]:

$F\left(t_{o}\right)=\int_{o}^{t} f\left(t_{o}\right) d t_{o}$

gde je $f\left(t_{o}\right)$ - gustina raspodele verovatnoće vremena trajanja postupaka održavanja.

Funkcija gustine raspodele verovatnoće vremena trajanja postupaka održavanja karakteriše pogodnost održavanja sa svim njegovim uticajnim faktorima i dejstvom na održavanje vozila.

Funkcija pogodnosti održavanja izražava se kao kumulativna funkcija verovatnoće i ima isti smisao $u$ teoriji održavanja kao funkcija nepouzdanosti $u$ teoriji pouzdanosti, što je prikazano na slici 1 [1].

Upoređivanjem dva sistema održavanja može se zaključiti da je povoljniji onaj koji za isto vreme ima veću vrednost funkcije pogodnosti održavanja, jer se pri tom postupci održavanja sprovode za kraće vreme, što je prikazano na slici 2 [1].

Na pogodnost održavanja utiče veći broj faktora kao što su: uslovi spoljne sredine, uslovi eksploatacije, kvalitet sistema održavanja, kvalitet logističke podrške, a najveći uticaj ima unutrašnja
NEPOUZDANOST

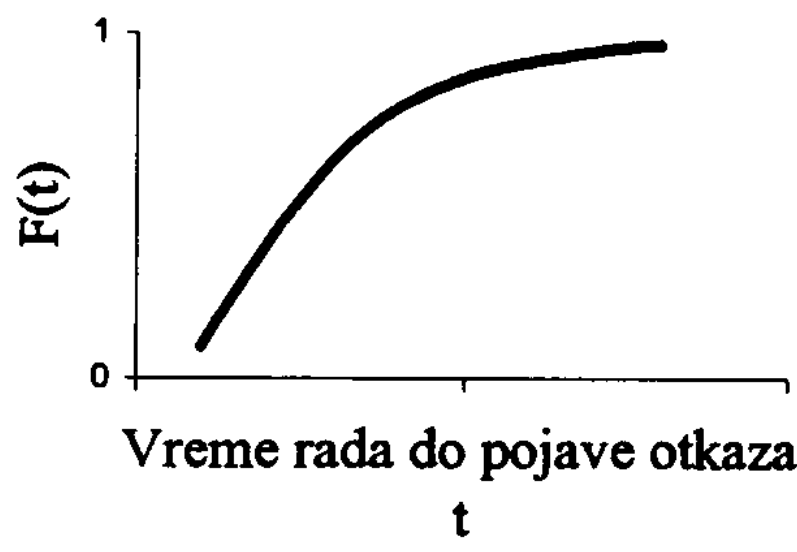

POGODNOST ODRŽAVANJA

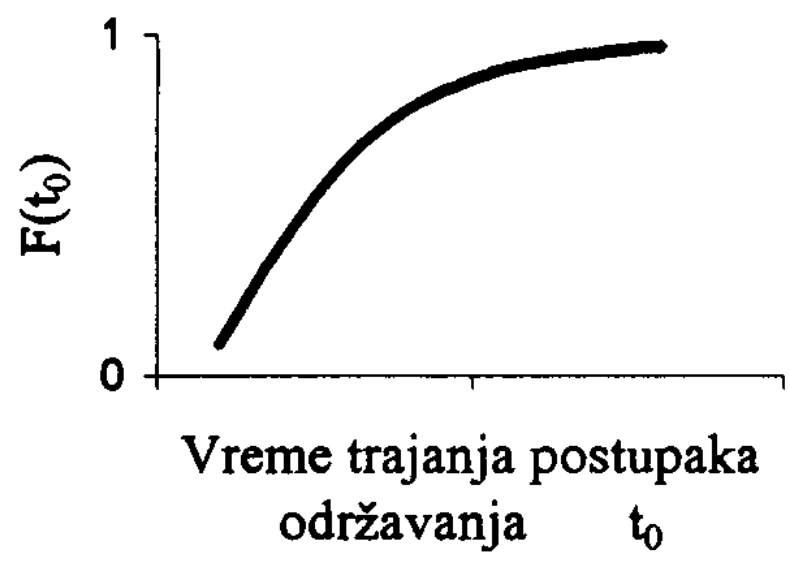

Sl 1 - Uporedni prikaz funkcije nepouzdanosti $i$ funkcije pogodnosti održavanja

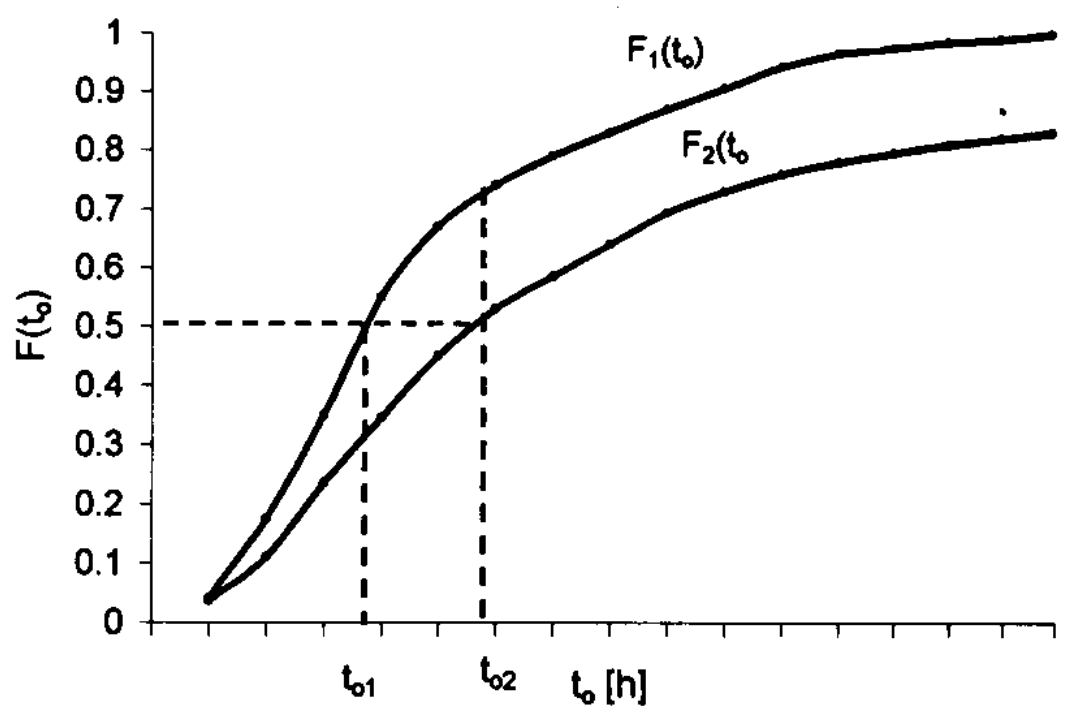

Sl. 2 - Dijagram zavisnosti vremena održavanja od funkcije pogodnosti održavanja

(ugrađena, sopstvena) ili konstrukcijska pogodnost održavanja ili popravljivost vozila.

Konstrukcijske karakteristike vozila u pogledu pogodnosti održavanja obuhvataju one faktore koji doprinose sma- 
njenju vremena zastoja i povećanju raspoloživosti vozila, a to su [2]:

- lakoća održavanja,

- svođenje zadataka preventivnog i korektivnog održavanja na minimum,

- svođenje logističke podrške na minimum, smanjivanjem broja i kvalifikacione strukture ljudstva, rezervnih delova i specijalne opreme za održavanje, podrške.

- smanjenje troškova logističke

Unutrašnja ili konstrukcijska pogodnost održavanja zavisi od unifikacije delova, sklopova i agregata vozila, standardizacije delova, pogodnosti za dijagnostiku, tehnologičnosti, manipulativnosti, dostupnosti pojedinih agregata, sklopova i delova $i$ vrste alata $i$ opreme koja se primenjuje za održavanje vozila. Konstrukcijske karakteristike vozila utiču na pogodnost njegovog održavanja preko brzine sprovođenja postupaka održavanja, što je tehnološka prilagođenost vozila održavanju i podrazumeva pristupačnost mestima za održavanje, složenost operacija rasklapanja i sklapanja, itd. [3].

Konstrukcijska pogodnost vozila za održavanje predstavlja sposobnost vozila da zadrži ispravno stanje putem preventivnog održavanja, ili da se vrati $u$ ispravno stanje putem korektivnog održavanja. Pogodnost vozila za održavanje smanjuje vreme vozila „u otkazu“ čime se povećava gotovost i raspoloživost vozila, a time i njegova ukupna efektivnost.

Istraživanja u ovoj oblasti pokazuju da se log-normalna raspodela najčešće koristi za interpretaciju raspodele funkcije pogodnosti održavanja, kada su postupci održavanja praćeni dužim čekanjima, dok je korišćenje Vejbulove raspodele prihvatljivije kada je razlika između vremena aktivnog održavanja i ukupnog vremena u otkazu mala $[1,3]$.
Za utvrđivanje teorijskih raspodela kojima se mogu najbolje aproksimirati empirijski podaci koriste se dve metodologije testiranja neparametarskih hipoteza [2]: grafičke i analitičke metode.

Grafičke metode obuhvataju konstruisanje papira verovatnoce, konstruisanje histograma, konstruisanje poligona ili funkcije kumulativne raspodele.

Analitičke metode obuhvataju test Kolmogorov-Smirnova, test Hi-kvadrata ili test Pirsona, test Romanovskog, test fon Missesa i mnoge druge.

Funkcija pogodnosti održavanja $\mathrm{F}\left(\mathrm{t}_{\mathrm{o}}\right)$ za log-normalnu raspodelu dobija se prema sledećem izrazu [2]:

$$
F\left(t_{o}\right)=\int_{o}^{t} \frac{1}{t_{o} \sigma \sqrt{2 \pi}} e^{-\frac{1}{2}\left(\frac{\operatorname{lnt}_{o}-m_{o}}{\sigma}\right)^{2}} d t
$$

Funkcija pogodnosti održavanja $\mathrm{F}\left(\mathrm{t}_{\mathrm{o}}\right)$ prema Vejbulovoj raspodeli dobija se iz jednačine [2]:

$$
F\left(t_{o}\right)=1-e^{-\left(\frac{t}{\eta}\right)^{\beta}}
$$

Funkcija pogodnosti održavanja $\mathrm{F}\left(\mathrm{t}_{\mathrm{o}}\right)$, prema gama-raspodeli, dobija se iz jednacine [2]:

$$
F\left(t_{o}\right)=\frac{1}{\eta \Gamma(\beta)} \int_{0}^{t}\left(\frac{t}{\eta}\right)^{\beta-1} e^{-\frac{t}{\eta}} d t
$$

$\mathrm{Na}$ osnovu podataka dobijenih iz eksploatacije za vremena korektivnog održavanja motora konkretnog vozila specijalne namene izvršiće se određivanje funkcije pogodnosti održavanja kao konstrukcijske karakteristike.

$\mathrm{Na}$ osnovu dobijenih rezultata, a na osnovu srednjeg vremena trajanja aktivnog održavanja, proceniće se, da li navedeni motor ispunjava taktičko-tehničke zahteve date standardom SNO 1096/85. 
Određivanje pogodnosti održavanja motora vozila specijalne namene

$\mathrm{Na}$ osnovu empirijskih podataka datih u tabeli 1 , koji se odnose na trajanje pojedinih vremena korektivnog održavanja, odrediće se kvantitativni pokazatelji pogodnosti održavanja motora konkretnog vozila specijalne namene, kao njegove konstrukcijske karakteristike.

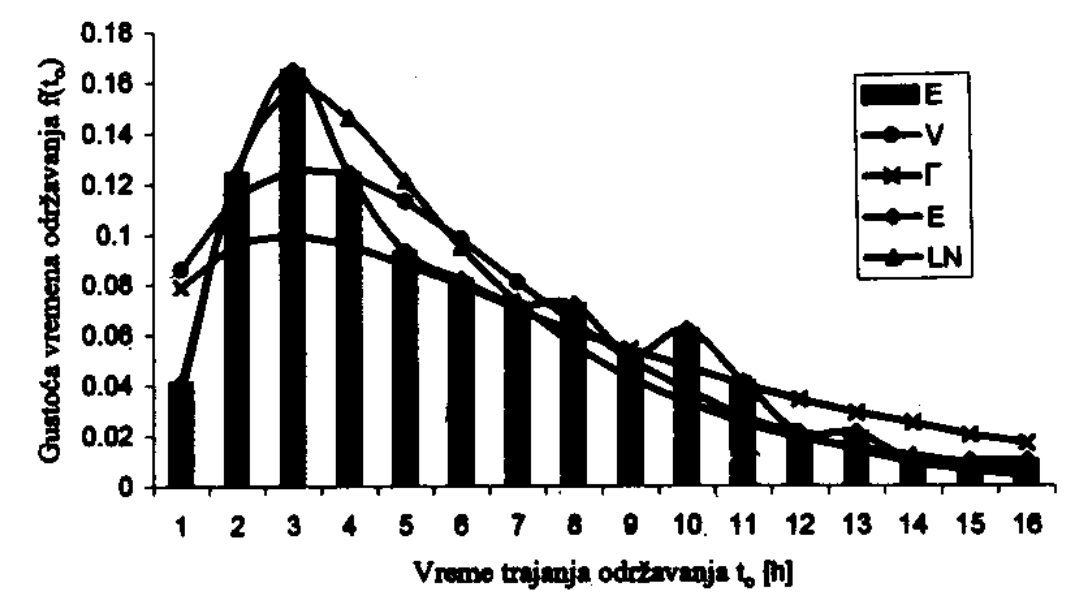

Sl. 3 - Histogram i dijagrami raspodele gustine vremena korektivnog održavanja u zavisnosti od vremena održavanja
Pokazatelji pogodnosti održavanja motora dobijeni na osnovu empirijskih podataka, prikazani su u tabeli 2 .

Histogram frekvencija pojavljivanja vremena trajanja održavanja, kao i raspodela funkcije gustoće vremena trajanja održavanja na osnovu empirijskih podataka, na osnovu lognormalne, Vejbulove i gama-raspodele grafički je prikazano na slici 3.

\section{Aproksimacija empirijskih podataka log-normalnom raspodelom}

Dobijena empirijska raspodela aproksimirana je log-normalnom raspodelom na osnovu koje su dobijene sledeće karakteristike statističkog skupa:

- srednje vreme trajanja aktivnog održavanja $\mathrm{t}_{\mathrm{osr}}=5,5 \mathrm{~h}$,

- standardno odstupanje $S=3,5 \mathrm{~h}$,

- srednja vrednost prirodnog loga-

Vremena aktivnog korektivnog održavanja motora

Tabela 1

\begin{tabular}{|c|c|c|c|c|c|c|c|}
\hline $\begin{array}{c}\text { Red. br. } \\
\text { otkaza }\end{array}$ & $\begin{array}{c}\text { Vreme } \\
\text { održ. }\end{array}$ & $\begin{array}{c}\text { Red. br. } \\
\text { otkaza }\end{array}$ & $\begin{array}{c}\text { Vreme } \\
\text { održ. }\end{array}$ & $\begin{array}{c}\text { Red. br. } \\
\text { otkaza }\end{array}$ & $\begin{array}{c}\text { Vreme } \\
\text { održ. }\end{array}$ & $\begin{array}{c}\text { Red. br. } \\
\text { otkaza }\end{array}$ & $\begin{array}{r}\text { Vreme } \\
\text { održ. }\end{array}$ \\
\hline 1. & 2,00 & 26. & 1,00 & 51. & 3,00 & 76. & 8,00 \\
2. & 8,00 & 27. & 4,00 & 52. & 9.00 & 77. & 4,00 \\
3. & 4,00 & 28. & 7,00 & 53. & 3,00 & 78. & 2,00 \\
4. & 1,00 & 29. & 12,00 & 54. & 9,00 & 79. & 3,00 \\
5. & 15,00 & 30. & 6,00 & 55. & 7,00 & 80. & 11,00 \\
6. & 2,00 & 31. & 12,00 & 56. & 5,00 & 81. & 5,00 \\
7. & 4,00 & 32. & 16,00 & 57. & 7,00 & 82. & 10,00 \\
8. & 10,00 & 33. & 6,00 & 58. & 6,00 & 83. & 5,00 \\
9. & 2,00 & 34. & 4,00 & 59. & 8,00 & 84. & 14,00 \\
10. & 3,00 & 35. & 3,00 & 60. & 2,00 & 85. & 4,00 \\
11. & 6,00 & 36. & 6,00 & 61. & 9,00 & 86. & 10,00 \\
12. & 8,00 & 37. & 2,00 & 62. & 3,00 & 87. & 5,00 \\
13. & 2,00 & 38. & 11,00 & 63. & 4,00 & 88. & 2,00 \\
14. & 3,00 & 39. & 4,00 & 64. & 6,00 & 89. & 5,00 \\
15. & 1,00 & 40. & 5,00 & 65. & 13,00 & 90. & 8.00 \\
16. & 3,00 & 41. & 3,00 & 66. & 9,00 & 91. & 7,00 \\
17. & 3,00 & 42. & 5,00 & 67. & 4,00 & 92. & 5,00 \\
18. & 2,00 & 43. & 2,00 & 68. & 13,00 & 93. & 3,00 \\
19. & 3,00 & 44. & 1,00 & 69. & 10,00 & 94. & 9,00 \\
20. & 7,00 & 45. & 4,00 & 70. & 3,00 & 95. & 2,00 \\
21. & 6,00 & 46. & 8,00 & 71. & 7,00 & 96. & 10,00 \\
22. & 10,00 & 47. & 11,00 & 72. & 4,00 & 97. & 4,00 \\
23. & 7,00 & 48. & 5,00 & 73. & 3,00 & & \\
24. & 3,00 & 49. & 3,00 & 74. & 2,00 & & \\
25. & 8,00 & 50. & 11,00 & 75. & 5,00 & & \\
\hline
\end{tabular}


Procenjeni pokazatelji pogodnosti održavanja motora na osnovu empirijskih podataka

\begin{tabular}{|c|c|c|c|c|c|}
\hline $\begin{array}{c}\text { Red. } \\
\text { br. }\end{array}$ & $\begin{array}{c}\text { Vreme } \\
\text { održavanja } \\
\mathbf{t}_{\mathrm{o}}(\mathrm{h})\end{array}$ & $\begin{array}{c}\text { Frekvencija } \\
\text { pojavljivanja } \\
\text { vremena } \\
\text { održavanja } \\
\end{array}$ & $\begin{array}{c}\text { Kumulativna } \\
\text { frekv. vrem. } \\
\text { održavanja }\end{array}$ & $\begin{array}{l}\text { Funkcija gustine } \\
\text { rasp. vrem. } \\
\text { održavanja } f\left(t_{o}\right)\end{array}$ & $\begin{array}{c}\text { Funkcija } \\
\text { pogodnosti } \\
\text { održavanja } \\
F\left(t_{o}\right)\end{array}$ \\
\hline $\begin{array}{r}1 . \\
2 . \\
3 . \\
4 . \\
5 . \\
6 . \\
7 . \\
8 . \\
9 . \\
10 . \\
11 . \\
12 . \\
13 . \\
14 . \\
15 . \\
16 .\end{array}$ & $\begin{array}{r}1,00 \\
2,00 \\
3,00 \\
4,00 \\
5,00 \\
6,00 \\
7,00 \\
8,00 \\
9,00 \\
10,00 \\
11,00 \\
12,00 \\
13,00 \\
14,00 \\
15,00 \\
16,00\end{array}$ & $\begin{array}{r}4 \\
12 \\
16 \\
12 \\
9 \\
8 \\
7 \\
7 \\
5 \\
6 \\
4 \\
2 \\
2 \\
1 \\
1 \\
1\end{array}$ & $\begin{array}{c}4 \\
16 \\
32 \\
44 \\
53 \\
61 \\
68 \\
75 \\
80 \\
86 \\
90 \\
92 \\
94 \\
95 \\
96 \\
97\end{array}$ & $\begin{array}{l}0,041 \\
0,124 \\
0,165 \\
0,124 \\
0,093 \\
0,082 \\
0,072 \\
0,072 \\
0,052 \\
0,062 \\
0,041 \\
0,021 \\
0,021 \\
0,010 \\
0,010 \\
0,010\end{array}$ & $\begin{array}{l}0,041 \\
0,165 \\
0,330 \\
0,454 \\
0,547 \\
0,629 \\
0,701 \\
0,773 \\
0,825 \\
0,887 \\
0,928 \\
0,949 \\
0,970 \\
0,980 \\
0,990 \\
0,999\end{array}$ \\
\hline
\end{tabular}

ritma od trajanja vremena održavanja $\mathrm{m}_{\mathrm{o}}=1,57$,

- standardno odstupanje prirodnog logaritma od vremena održavanja $\sigma=0,66$.

Pokazatelji pogodnosti održavanja za log-normalnu raspodelu prikazani su u tabeli 3.

Tabela 3

Vrednost pokazatelja pogodnosti održavanja motora na osnovu log-normalne raspodele

\begin{tabular}{|c|c|c|c|}
\hline $\begin{array}{c}\text { Red. } \\
\text { br. }\end{array}$ & $\begin{array}{c}\text { Vreme } \\
\text { održavanja } \\
\mathrm{t}_{\mathrm{o}}(\mathrm{h})\end{array}$ & $\begin{array}{c}\text { Funkcija gus- } \\
\text { tine raspodele } \\
\text { vremena odr- } \\
\left.\text { žavanja } \mathrm{f}_{\mathrm{o}}\right)\end{array}$ & $\begin{array}{c}\text { Funkcija } \\
\text { pogodnosti } \\
\text { održavanja } \\
\mathrm{F}\left(\mathrm{t}_{\mathrm{o}}\right)\end{array}$ \\
\hline 1. & 1,00 & 0,036 & 0,009 \\
2. & 2,00 & 0,125 & 0,092 \\
3. & 3,00 & 0,157 & 0,239 \\
4. & 4,00 & 0,146 & 0,389 \\
5. & 5,00 & 0,121 & 0,524 \\
6. & 6,00 & 0,095 & 0,633 \\
7. & 7,00 & 0,073 & 0,716 \\
8. & 8,00 & 0,056 & 0,782 \\
9. & 9,00 & 0,043 & 0,832 \\
10. & 10,00 & 0,033 & 0,869 \\
11. & 11,00 & 0,025 & 0,896 \\
12. & 12,00 & 0,019 & 0,918 \\
13. & 13,00 & 0,015 & 0,934 \\
14. & 14,00 & 0,012 & 0,948 \\
15. & 15,00 & 0,009 & 0,958 \\
16. & 16,00 & 0,007 & 0,966 \\
\hline
\end{tabular}

Testiranje log-normalne raspodele

Odstupanje vrednosti funkcije pogodnosti održavanja na osnovu log-normalne raspodele od vrednosti koje su procenjene na osnovu empirijskih podataka prikazano je u tabeli 4 i na slici 4 .

\section{Test Kolmogorov-Smirnova}

Za stepen značajnosti $\alpha=0,20 \Rightarrow$ $\lambda=1,07$. Najveća razlika između teorijske raspodele $F_{t}(t)$ i procenjenih vredno-

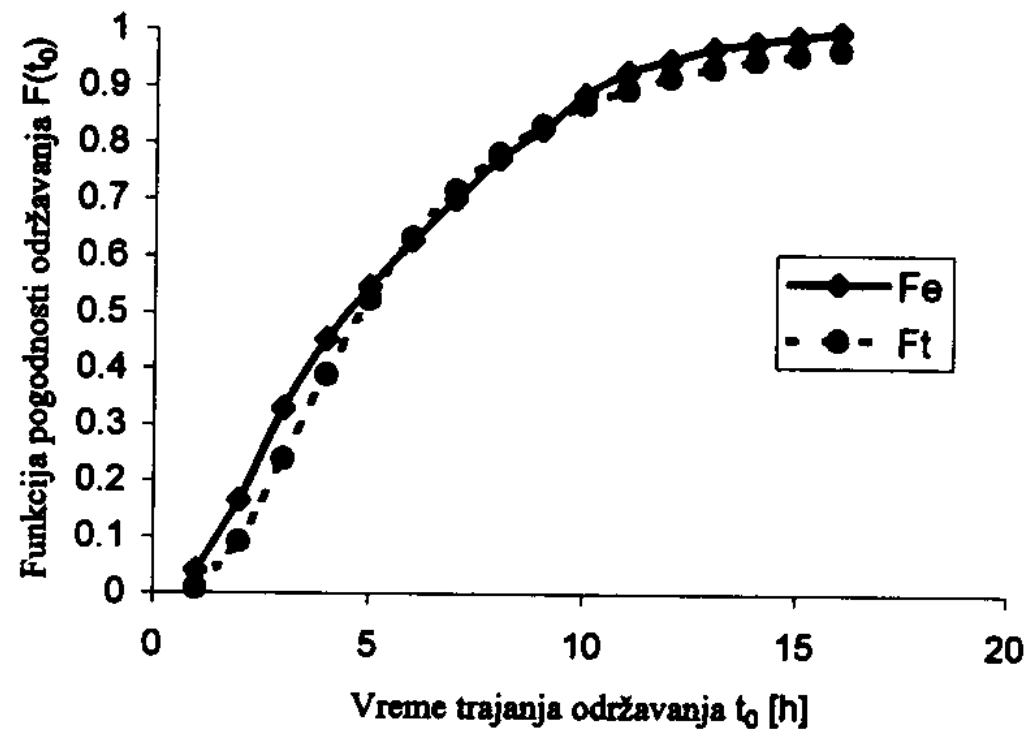

Sl. 4 - Dijagram odstupanja funkcije pogodnosti održavanja dobijene na osnovu log-normalne raspodele od vrednosti procenjenih na osnovu empirijskih podataka 
Tabela 4

Odstupanja vrednosti funkcije pogodnosti održavanja na osnovu log-normalne raspodele od vrednosti procenjenih na osnovu empirijskih podataka

\begin{tabular}{|c|c|c|c|c|}
\hline $\begin{array}{c}\text { Red. } \\
\text { br. }\end{array}$ & $\begin{array}{c}\text { Vreme } \\
\text { održavanja } \\
\mathrm{t}(\mathrm{h})\end{array}$ & $\mathrm{F}_{\mathrm{e}}\left(\mathrm{t}_{\mathrm{o}}\right)$ & $\mathrm{F}_{\mathrm{t}}\left(\mathrm{t}_{\mathrm{o}}\right)$ & $\Delta$ \\
\hline 1. & 1,00 & 0,041 & 0,009 & 0,032 \\
2. & 2,00 & 0,165 & 0,092 & 0,073 \\
3. & 3,00 & 0,330 & 0,239 & 0,091 \\
4. & 4,00 & 0,454 & 0,389 & 0,065 \\
5. & 5,00 & 0,547 & 0,524 & 0,023 \\
6. & 6,00 & 0,629 & 0,633 & 0,004 \\
7. & 7,00 & 0,701 & 0,716 & 0,015 \\
8. & 8,00 & 0,773 & 0,782 & 0,009 \\
9. & 9,00 & 0,825 & 0,832 & 0,007 \\
10. & 10,00 & 0,887 & 0,869 & 0,018 \\
11. & 11,00 & 0,928 & 0,896 & 0,032 \\
12. & 12,00 & 0,949 & 0,918 & 0,031 \\
13. & 13,00 & 0,970 & 0,934 & 0,036 \\
14. & 14,00 & 0,980 & 0,948 & 0,032 \\
15. & 15,00 & 0,990 & 0,958 & 0,032 \\
16. & 16,00 & 0,999 & 0,966 & 0,033 \\
\hline
\end{tabular}

sti $F_{e}(t)$ na osnovu empirijskih podataka pojavljuje se za rezultat na rednom broju tri i iznosi $D_{\max }=0,091$. Za broj elemenata $\mathrm{n}=97$ i $\alpha=0,20$ dozvoljena vrednost razlike je $D_{\text {doz }}=\lambda / \sqrt{n}=0,109$. Pošto je $D_{\max }<D_{\text {doz }}$ ova teorijska aproksimativna raspodela zadovoljava test Kolmogorov-Smirnova.

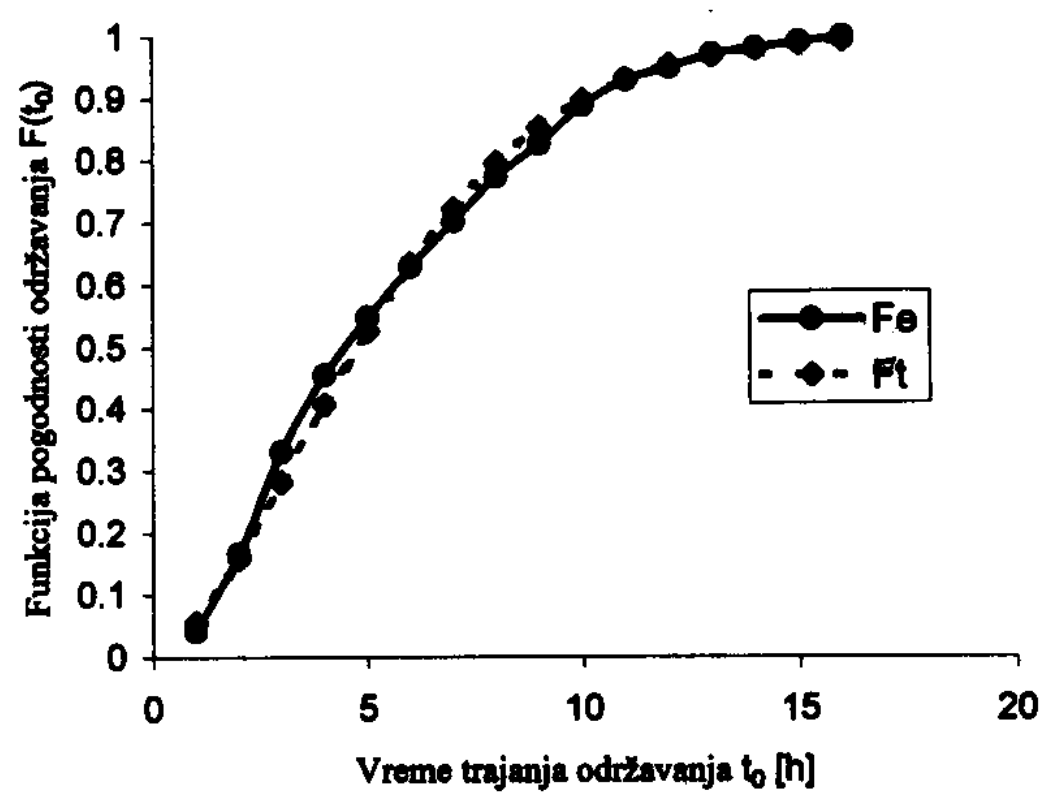

Sl. 5 - Dijagram odstupanja funkcije pogodnosti održavanja dobijene na osnovu Vejbulove raspodele od vrednosti procenjenih na osnovu empirijskih podataka

\section{Test Pirsona}

Pošto je izračunata vrednost $\chi^{2}=0,226$ manja od tablične vrednosti $\chi_{0,99}^{2}=4,107 \mathrm{za} 13$ stepeni slobode, teorijska aproksimativna raspodela zadovoljava test Pirsona.

\section{Test Romanovskog}

Pošto je izračunata vrednost za test Romanovskog 2,5052 $<3$, teorijska aproksimativna raspodela zadovoljava ovaj test.

\section{Aproksimacija empirijskih podataka Vejbulovom raspodelom}

Dobijena empirijska raspodela aproksimirana je i Vejbulovom dvoparametarskom raspodelom.

$\mathrm{Na}$ osnovu proračuna dobijeni su parametri Vejbulove raspodele:

- parametar razmere $\eta=5,5(\mathrm{~h})$,

- parametar oblika $\beta=1,6$.

Pokazatelji pogodnosti održavanja motora na osnovu Vejbulove raspodele prikazani su u tabeli 5 .

Tabela 5

Vrednosti pokazatelja pogodnosti održavanja motora na osnovu Vejbulove raspodele

\begin{tabular}{|c|c|c|c|}
\hline $\begin{array}{c}\text { Red. } \\
\text { br. }\end{array}$ & $\begin{array}{c}\text { Vreme } \\
\text { održavanja } \\
\mathrm{t}_{\mathrm{o}}(\mathrm{h})\end{array}$ & $\begin{array}{c}\text { Funkcija gus- } \\
\text { tine raspodele } \\
\text { vremena odr- } \\
\left.\text { žavanja } \mathrm{f}_{\mathrm{o}}\right)\end{array}$ & $\begin{array}{c}\text { Funkcija } \\
\text { pogodnosti } \\
\text { održavanja } \\
\mathrm{F}\left(\mathrm{t}_{\mathrm{o}}\right)\end{array}$ \\
\hline 1. & 1,00 & 0,086 & 0,055 \\
2. & 2,00 & 0,116 & 0,158 \\
3. & 3,00 & 0,126 & 0,281 \\
4. & 4,00 & 0,124 & 0,407 \\
5. & 5,00 & 0,113 & 0,526 \\
6. & 6,00 & 0,098 & 0,632 \\
7. & 7,00 & 0,081 & 0,722 \\
8. & 8,00 & 0,065 & 0,795 \\
9. & 9,00 & 0,050 & 0,852 \\
10. & 10,00 & 0,038 & 0,896 \\
11. & 11,00 & 0,027 & 0,929 \\
12. & 12,00 & 0,020 & 0,952 \\
13. & 13,00 & 0,014 & 0,968 \\
14. & 14,00 & 0,009 & 0,979 \\
15. & 15,00 & 0,006 & 0,987 \\
16. & 16,00 & 0,004 & 0,992 \\
\hline
\end{tabular}




\section{Testiranje Vejbulove raspodele}

Odstupanje vrednosti funkcije pogodnosti održavanja na osnovu Vejbulove raspodele od vrednosti procenjenih na osnovu empirijskih podataka prikazano je u tabeli 6 i na slici 6 .

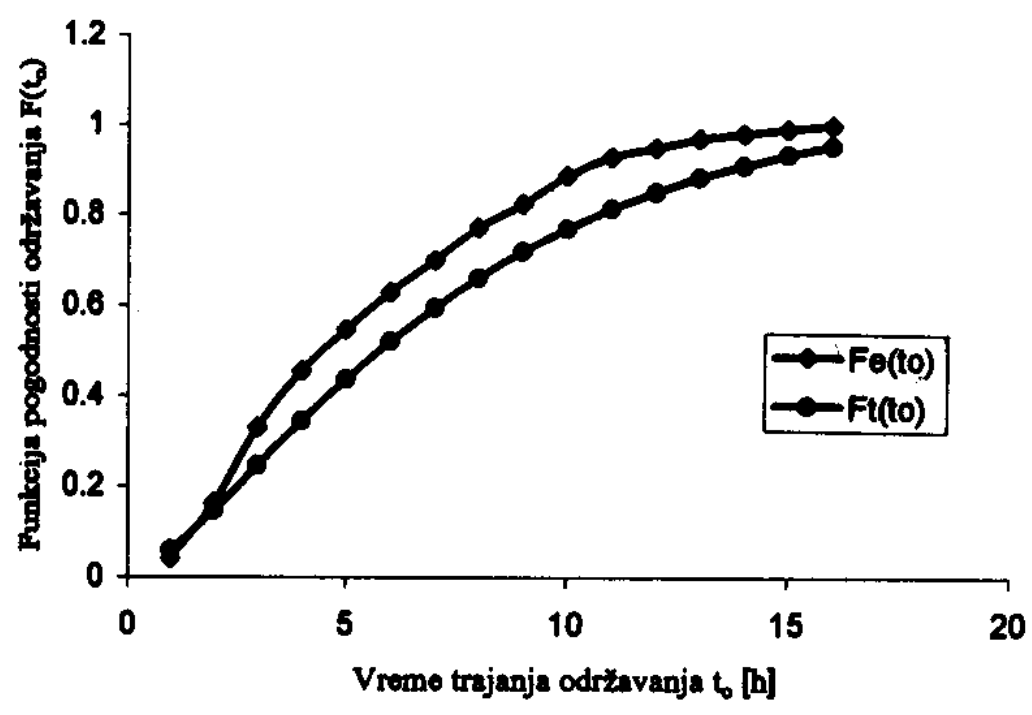

Sl. 6 - Dijagram odstupanja funkcije pogodnosti održavanja dobijene na osnovu gama-raspodele od vrednosti procenjenih na osnovu empirijskih podataka

\section{Test Kolmogorov-Smirnova}

Za stepen značajnosti $\alpha=0,20 \Rightarrow$ $\lambda=1,07$. Najveća razlika između teorijske raspodele $F_{t}(t)$ i procenjenih vredno-

Tabela 6

Odstupanja vrednosti funkcije pogodnosti održavanja na osnovu Vejbulove raspodele od vrednosti procenjenih na osnovu empirijskih podataka

\begin{tabular}{|c|c|c|c|c|}
\hline $\begin{array}{c}\text { Red. } \\
\text { broj }\end{array}$ & $\begin{array}{c}\text { Vreme } \\
\text { održavanja } \\
\mathrm{t}_{\mathrm{o}}(\mathrm{i})\end{array}$ & $\mathrm{F}_{\mathrm{e}}\left(\mathrm{t}_{\mathrm{o}}\right)_{\mathrm{i}}$ & $\mathrm{F}_{\mathrm{t}}\left(\mathrm{t}_{\mathrm{o}}\right)_{\mathrm{i}}$ & $\Delta$ \\
\hline 1. & 1,00 & 0,041 & 0,055 & 0,014 \\
2. & 2,00 & 0,165 & 0,158 & 0,007 \\
3. & 3,00 & 0,330 & 0,281 & 0,049 \\
4. & 4,00 & 0,454 & 0,407 & 0,047 \\
5. & 5,00 & 0,547 & 0,526 & 0,021 \\
6. & 6,00 & 0,629 & 0,632 & 0,003 \\
7. & 7,00 & 0,701 & 0,722 & 0,021 \\
8. & 8,00 & 0,773 & 0,795 & 0,022 \\
9. & 9,00 & 0,825 & 0,852 & 0,027 \\
10. & 10,00 & 0,887 & 0,896 & 0,009 \\
11. & 11,00 & 0,928 & 0,929 & 0,001 \\
12. & 12,00 & 0,949 & 0,952 & 0,003 \\
13. & 13,00 & 0,970 & 0,968 & 0,002 \\
14. & 14,00 & 0,980 & 0,979 & 0,001 \\
15. & 15,00 & 0,990 & 0,987 & 0,003 \\
16. & 16,00 & 0,999 & 0,992 & 0,007 \\
\hline
\end{tabular}

sti na osnovu empirijskih podataka $F_{e}(t)$ javlja se za rezultat na rednom broju tri tabele 6 i iznosi $D_{\max }=0,049$. Za broj elemenata $n=97$ i $\lambda=0,20$ dozvoljena vrednost razlike je $D_{\text {doz }}=\lambda /$ $\sqrt{\mathrm{n}}=0,109$. Pošto je $D_{\max }<D_{\text {doz }}$ teorijska aproksimativna Vejbulova raspodela zadovoljava ovaj test.

\section{Test Pirsona}

Pošto je izračunata vrednost $\chi^{2}=0,0209$ manja od tablične vrednosti $\chi_{0,99}^{2}=4,107$ za 13 stepeni slobode, teorijska aproksimativna Vejbulova raspodela zadovoljava test Pirsona.

\section{Test Romanovskog}

Pošto je izračunata vrednost za test Romanovskog 2,5454 < 3, teorijska aproksimativna Vejbulova raspodela zadovoljava ovaj test.

\section{Aproksimacija empirijskih podataka gama-raspodelom}

Dobijena empirijska raspodela aproksimirana je i gama-raspodelom.

Pokazatelji pogodnosti održavanja za gama-raspodelu prikazani su u tabeli 7 .

\section{Testiranje gama-raspodele}

Odstupanje vrednosti funkcije pogodnosti održavanja na osnovu gama-raspodele od vrednosti procenjenih na osnovu empirijskih podataka prikazano je u tabeli 8 i na slici 6 .

\section{Test Kolmogorov-Smirnova}

Najveća razlika između teorijske raspodele $F_{t}(t)$ i procenjenih vrednosti $F_{e}(t)$ na osnovu empirijskih podataka javlja se 
Tabela 7

Vrednosti pokazatelja pogodnosti održavanja motora na osnovu gama-raspodele

\begin{tabular}{|c|c|c|c|}
\hline $\begin{array}{c}\text { Red. } \\
\text { br. }\end{array}$ & $\begin{array}{c}\text { Vreme } \\
\text { održavanja } \\
\mathrm{t}_{\mathrm{o}}(\mathrm{h})\end{array}$ & $\begin{array}{c}\text { Funkcija gus- } \\
\text { tine raspodele } \\
\text { vremena odr- } \\
\text { žavanja } \mathrm{f}\left(\mathrm{t}_{\mathrm{o}}\right)\end{array}$ & $\begin{array}{c}\text { Funkcija } \\
\text { pogodnosti } \\
\text { održavanja } \\
\mathrm{F}\left(\mathrm{t}_{\mathrm{o}}\right)\end{array}$ \\
\hline 1. & 1,00 & 0,079 & 0,059 \\
2. & 2,00 & 0,097 & 0,147 \\
3. & 3,00 & 0,100 & 0,246 \\
4. & 4,00 & 0,096 & 0,344 \\
5. & 5,00 & 0,088 & 0,436 \\
6. & 6,00 & 0,080 & 0,520 \\
7. & 7,00 & 0,070 & 0,595 \\
8. & 8,00 & 0,061 & 0,661 \\
9. & 9,00 & 0,054 & 0,719 \\
10. & 10,00 & 0,047 & 0,770 \\
11. & 11,00 & 0,040 & 0,814 \\
12. & 12,00 & 0,034 & 0,851 \\
13. & 13,00 & 0,029 & 0,883 \\
14. & 14,00 & 0,025 & 0,910 \\
15. & 15,00 & 0,020 & 0,933 \\
16. & 16,00 & 0,017 & 0,952 \\
\hline
\end{tabular}

Tabela 8

Odstupanja vrednosti funkcije pogodnosti održavanja na osnovu gama-raspodele od vrednosti procenjenih na osnovu empirijskih podataka

\begin{tabular}{|c|c|c|c|c|}
\hline $\begin{array}{c}\text { Red. } \\
\text { broj }\end{array}$ & $\begin{array}{c}\text { Vreme } \\
\text { održavanja } \\
\mathrm{t}_{\mathrm{o}}(\mathrm{i})\end{array}$ & $\mathrm{F}_{\mathrm{e}}\left(\mathrm{t}_{\mathrm{o}}\right)_{\mathrm{i}}$ & $\mathrm{F}_{\mathrm{t}}\left(\mathrm{t}_{\mathrm{o}}\right)_{\mathrm{i}}$ & $\Delta$ \\
\hline 1. & 1,00 & 0,041 & 0,059 & 0,018 \\
2. & 2,00 & 0,165 & 0,147 & 0,018 \\
3. & 3,00 & 0,330 & 0,246 & 0,084 \\
4. & 4,00 & 0,454 & 0,344 & 0,110 \\
5. & 5,00 & 0,547 & 0,436 & 0,111 \\
6. & 6,00 & 0,629 & 0,520 & 0,109 \\
7. & 7,00 & 0,701 & 0,595 & 0,106 \\
8. & 8,00 & 0,773 & 0,661 & 0,112 \\
9. & 9,00 & 0,825 & 0,719 & 0,106 \\
10. & 10,00 & 0,887 & 0,770 & 0,117 \\
11. & 11,00 & 0,928 & 0,814 & 0,114 \\
12. & 12,00 & 0,949 & 0,851 & 0,098 \\
13. & 13,00 & 0,970 & 0,883 & 0,087 \\
14. & 14,00 & 0,980 & 0,910 & 0,070 \\
15. & 15,00 & 0,990 & 0,933 & 0,057 \\
16. & 16,00 & 0,999 & 0,952 & 0,047 \\
\hline
\end{tabular}

na rednom broju 10 i iznosi $D_{\max }=0,117$. Za stepen značajnosti $\alpha=0,20$ i broj elemenata $\mathrm{n}=16$ dozvoljena vrednost razlike je $D_{\text {doz }}=0,258$. Pošto je $D_{\max }<$ $\mathrm{D}_{\mathrm{doz}}$ ova teorijska aproksimativna raspodela zadovoljava test Kolmogorov-Smirnova.

\section{Test Pirsona}

Pošto je izračunata vrednost $\chi^{2}=0,241$ manja od tablične vrednosti $\chi_{0,99}^{2}=4,107 \mathrm{za} 13$ stepeni slobode, teorijska aproksimativna raspodela zadovoljava test Pirsona.

\section{Test Romanovskog}

Pošto je izračunata vrednost za test Romanovskog 2,5024 $<3$, teorijska aproksimativna raspodela zadovoljava ovaj test.

Iz dobijenih rezultata može se videti da i log-normalna i gama i Vejbulova raspodela dobro aproksimiraju procenjene vrednosti iz empirijskih podataka.

Da bi se videlo koja raspodela najbolje aproksimira empirijske podatke izvršeno je upoređivanje rezultata testiranja svih raspodela, što je prikazano u tabeli 9 .

Upoređivanjem rezultata testiranja može se zaključiti da Vejbulova raspodela znatno bolje zadovoljava test Kolmogorov-Smirnova, nešto bolje zadovoljava test Pirsona, dok gama i log-normalna nešto bolje zadovoljavaju test Romanovskog. Dakle, Vejbulova raspodela najbolje aproksimira empirijske podatke dobijene iz eksploatacije.

Iz dijagrama sa slika 4,5 i 6 može se videti da se $50 \%$ svih korektivnih održavanja navedenog motora obavi za manje od 5 časova rada, $30 \%$ korektivnih održavanja za manje od 3 casa rada, dok

Tabela 9

Uporedni prikaz pokazatelja testiranja teorijskih raspodela

\begin{tabular}{|l|c|c|c|}
\hline Test & $\begin{array}{c}\text { Kolmogorov } \\
- \text { Smirnova } \\
\mathrm{D}_{\max }\end{array}$ & $\begin{array}{c}\text { Pirsona } \\
\chi^{2}\end{array}$ & $\begin{array}{c}\text { Romanovskog } \\
\left|\chi^{2}-\mathrm{k}\right| / \sqrt{2 \mathrm{k}}\end{array}$ \\
\hline log-normalalna & 0,091 & 0,226 & 2,5052 \\
\hline Vejbulova & 0,049 & 0,209 & 2,5454 \\
\hline gama & 0,117 & 0,241 & 2,5024 \\
\hline
\end{tabular}


se samo $10 \%$ korektivnih održavanja obavi za više od 10 časova rada.

Pored toga, upoređivanjem dobijenih podataka za srednje vreme aktivnog korektivnog održavanja od 5 časova rada sa taktičko-tehničkim zahtevima, datim u SNO 1096/85 u tabeli 3.7.1. na rednom broju 6 , za mašine i agregate koje iznosi 10 časova za srednje vreme trajanja otklanjanja neispravnosti na nivou srednjeg remonta, može se zaključiti da navedeni motor ima dobre pogodnosti održavanja i u potpunosti ispunjava taktičko-tehničke zahteve u tom pogledu.

\section{Zaključak}

$\mathrm{U}$ radu je na osnovu aktivnog vremena korektivnog održavanja 97 motora istog tipa vozila u realnim uslovima eksploatacije praktično prikazana primena jedne od metoda za ocenjivanje pogodnosti održavanja, kao konstrukcijske karakteristike datog podsistema.

Vremena održavanja predstavljaju ukupno vreme aktivnog rada na korektivnom održavanju navedenog konkretnog podsistema vozila. Iz dobijenih rezultata može se videti da se raspodela vremena aktivnog korektivnog održavanja najpri- bližnije može opisati Vejbulovom raspodelom.

Iz dobijenih rezultata može se zakljuciti da se $30 \%$ svih korektivnih održavanja motora obavi za manje od 3 časa rada, $50 \%$ svih korektivnih održavanja za manje od 5 časova rada i samo $10 \%$ svih korektivnih održavanja obavi za više od 10 casova.

Upoređivanjem dobijenih rezultata sa taktičko-tehničkim zahtevima može se zaključiti da ih motor u potpunosti zadovoljava u pogledu pogodnosti održavanja za srednje vreme trajanja otklanjanja neispravnosti na nivou srednjeg remonta.

Primenom navedene metode može se odrediti pogodnost održavanja i ostalih podsistema, agregata i sklopova, kao i vozila u celini.

\section{Literatura:}

[1] Todorović, B.J.: Inžinjerstvo održavanja tehničkih sistema, Jugoslovensko društvo za motore i vozila, Beograd, 1993.

[2] Vujanovic, N.: Teorija pouzdanosti tehnickih sistema, Vojnoizdavački i novinski centar, Beograd, 1990.

[3] Krstic, V.B.: Eksploatacija motornih vozila i motora, Mašinski fakultet, Kragujevac, 1997.

[4] Zelenovic, D., Todorovic, B.J.: Efektivnost sistema u mašinstvu, Naučna knjiga, Beograd, 1990.

[5] Takticko-tehnicki zahtevi za razvoj tehnickih materijalnih sredstava, SNO 1096/85, Beograd, 1985.

[6] Brkic, Lj.: Optimizacija sistema održavanja motornih vozila specijalne namene, magistarski rad, Masinski fakultet, Kragujevac, 1998. 